\title{
Biochemical Composition and Enzymatic Activity of Aloe vera (Aloe barbadensis L.)
}

\author{
Chetna Gangwar, Pratibha Singh, Raj Narayan Kewat and Nitin Vikram*
}

\author{
Department of Biochemistry, Narendra Deva University of Agriculture and Technology \\ Kumarganj, Faizabad 224229, U. P., India \\ *Corresponding author
}

\section{A B S T R A C T}

\begin{tabular}{|l|}
\hline K e y w o r d s \\
Anthraquinones, \\
Cosmetic, Lignins, \\
Salicyclic acid, \\
Steroids and vitamins. \\
\hline Article Info \\
\hline $\begin{array}{l}\text { Accepted: } \\
\text { 26 September } 2017 \\
\text { Available Online: } \\
\text { 10 November } 2017\end{array}$ \\
\hline
\end{tabular}

Keywords

Anthraquinones,

Cosmetic, Lignins,

Steroids and vitamins.

Article Info

Accepted:

Available Online:

10 November 2017
Aloe vera has a long history as a medicinal plant with diverse therapeutic applications. This study determined biochemical composition and enzymatic activity of Aloe vera leaves. Five genotypes of aloe vera leaves were analysed biochemically and enzymatically. Germplasm IC-112517 showed maximum gel percentage (97.00\%), maximum moisture percentage (97.03) and IC-112527 contain maximum per cent of carbohydrate (64.20\%), total mineral $(11.10 \%)$ and total sugar content $(30.07 \%)$ and total chlorophyll content $(0.20$ $\mathrm{mg} / \mathrm{gm})$. The germplasm IC-285626 showed maximum per cent of crude fibre content (11.43\%). Germplasm IC- 112527 showed maximum catalase enzyme activity (1.92unit/ml) and peroxidase enzyme activity ( $1.67 \mathrm{unit} / \mathrm{ml})$. Overall this investigation has provided a succinct resume of information regarding the biochemical composition and enzymatic activity of Aloe vera leaves. It would be worthwhile embarking on an intensive scientific experimentation and investigation on this valuable medicinal plant and to promote its large scale utilization.

\section{Introduction}

Aloe vera (Aloe barbadensis) is a perennial, drought resisting succulent plant belonging to the Liliaceae family with its origin in the African continent. The Aloe vera plant has been known and used for centuries for its health, beauty, medicinal and skin care properties (Rai et al., 2011). The parenchyma cells contain a transparent mucilaginous jelly which is referred to as Aloe vera gel (Ramachandra and Rao, 2008). In India it is used as tonic for anemia, poor digestive function and liver disorders. Aloe vera is being used as an ingredient for functional food, mainly in the development of health drinks and beverages like tea, etc. (Singh et al., 2010). Aloe vera is the most commercialized aloe species and processing of the leaf pulp has become a large worldwide industry. In the food industry it has been used as a source of functional foods and as an ingredient in other food products for the production of gel containing health drinks and beverages. In the cosmetic and toiletry industry, it has been used as base material for the production of powders, capsule, creams, lotions, soaps, shampoos, facial cleansers, oils and other products for both external and internal uses for a wide variety of indications (Hamman, 2008; Haque et al., 2012). Aloe has broad range of pharmacological 
properties, including antiinflammatory, antiviral, antioxidative actions, antibacterial, immunostimulant, antifungal, analgesic, antitumor, antidiabetic and inhibition of tumor cells activation and proliferation (Ray et al., 2013).

\section{Materials and Methods}

Aloe barbadensis plants were collected from the experimental farm medicinal and aromatic plantsof NDUAT, Kumarganj, Faizabad. The collected Aloe vera leaves were cleaned, dry and chopped into small pieces by a chopper. The three leaves of Aloe vera plant were harvested and the peels from each leaf were removed and the total gel content was collected separately in each petridish. The gel per cent was calculated on the basis of following formula.

Gel Percentage $=\frac{\text { Weight of gel }}{\text { weight of leaf }} \times 100$

Then Aloe vera leaves dried in an oven for 16 hours. The dried mass was then crushed by a pestle and mortar. Finally, the brownish product was the desired Aloe verapowder. The physico-chemical properties of the product were analysed and the results are summarized. Moisture was estimated by drying the known amount of sample in an oven maintained at $55 \pm 22^{\circ} \mathrm{C}$ till it attained a constant weight. Moisture content was calculated by subtracting the dried weight from the fresh weight and expressed as percentage of fresh weight (Ranganna, 1986). Total mineral content was estimated by the method as described by Hart and Fisher (1971).

Total mineral content $(\%)=\frac{\text { weight of ash }}{\text { weight of sample }} \times 100$

Total carbohydrate in Aloe vera sample was analysed by method of Yemm and Willis
(1954) by using Anthrone reagent. Total sugar content analysed by Dubois et al., (1950) using phenol reagent. The content of crude fibre in dried Aloe vera gel were analysed by the method as described by Hart and Fisher (1971). The total chlorophyll content was estimated by the method of Arnon (1949) and results were expressed as $\mathrm{mg}$ per $100 \mathrm{~g}$ fresh weight. Catalase enzyme activity was measured by the method given by Sinha (1972) following reaction of potassium dichromate to chromic acetate by $\mathrm{H}_{2} \mathrm{O}_{2}$. Peroxidase enzyme activity was assayed by calorimetrically method as given by McCune and Galston (1959).

\section{Results and Discussion}

The results on identity, strength and assay of Aloe vera powder and proximate composition are shown in graph 1,2 and 3 respectively. The gel content in Aloe vera germplasm ranged from 96.33-97.00 per cent. Maximum gel content was found $97.00 \%$ in IC-283655 and IC-112517. Variation among the germplasm was found statistically nonsignificant. It may be caused due to environmental factors. Variation in gel content is closely related with O'Brien, et al., (2011), Ganesh et al., (2009), Roy et al., (2007).The moisture content is affected by the environmental factor such as temperature humidity etc. Maximum moisture content was recorded 97.03 per cent in IC-112517 which was statistically significant higher over all the germplasm. The results have a close agreement with the reports of Ganesh and Alagukannang (2009). The mineral content varied from 10.29-11.20 per cent in various germplasm of Aloe vera. Maximum mineral content was reported 11.20 per cent in IC112527 which was statistically significant superior among all the germplasm. These results have a close agreement with the finding of Varindra et al., (2011) and Rodriguez et al., (2010). 
The carbohydrate content varied from 60.87 to 64.20 per cent in various germplasm of Aloe vera. Maximum carbohydrate content was found 64.20 per cent in IC-112527 which was significantly superior over the rest of germplasm. These results are closely correlated with Moghaddasi and Verma (2011). Total sugar content ranged from 29.10-30.07 per cent in various germplasm of Aloe vera. Maximum total sugar content was observed 30.07 per cent in IC-112527 which was found statistically significant higher over the rest germplasm. These results are in close agreement to Varindra et al., (2011).

Crude fibre content varied from 10.62 to 11.43 per cent in various germplasm of Aloe vera. Maximum crude fibre content was found 11.43 per cent in IC-285626 which was statistically non-significant superior over the rest of germplasm.

Similar results were also observed by Hussain (2013) and Singh et al., (2010).
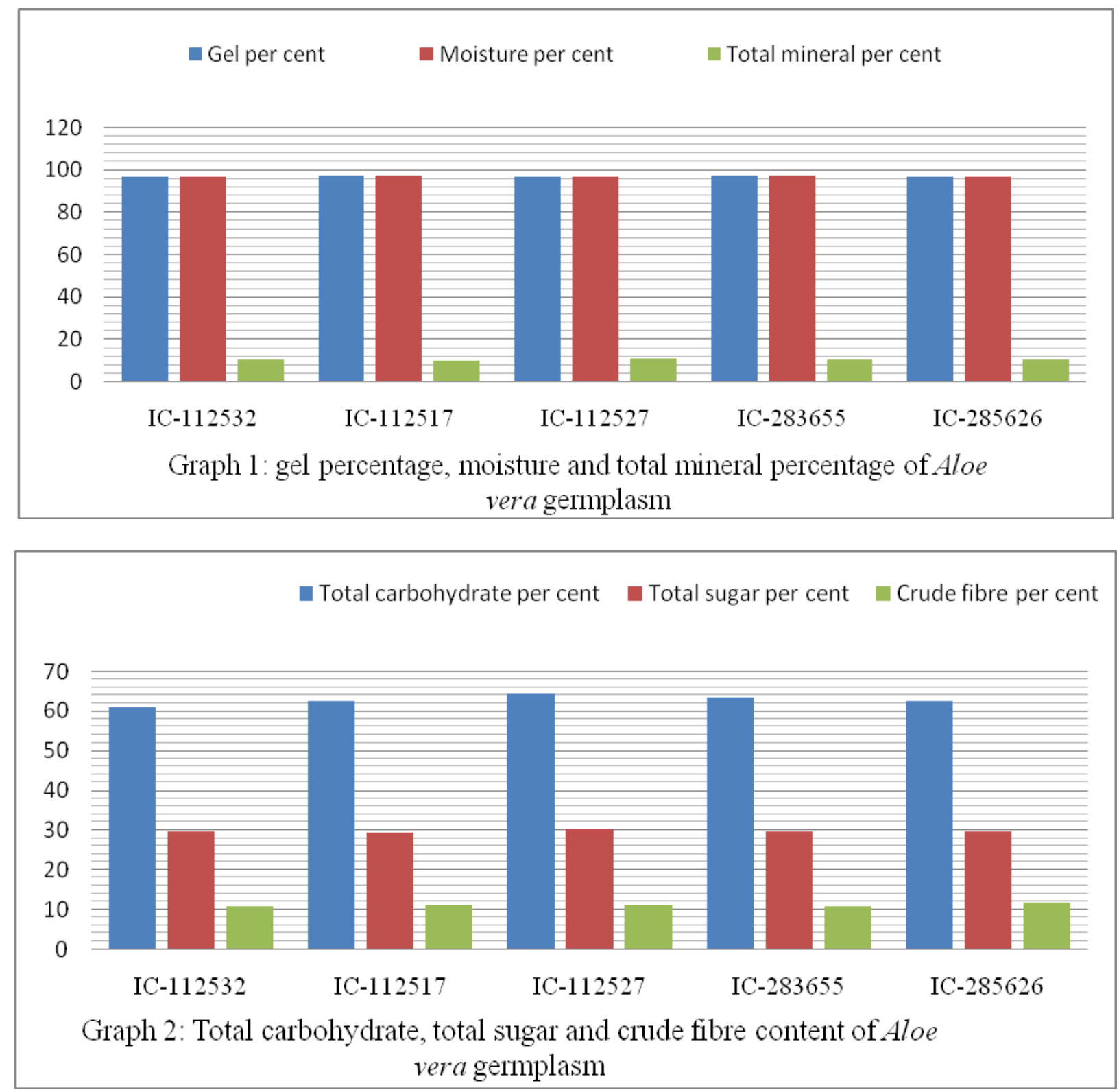


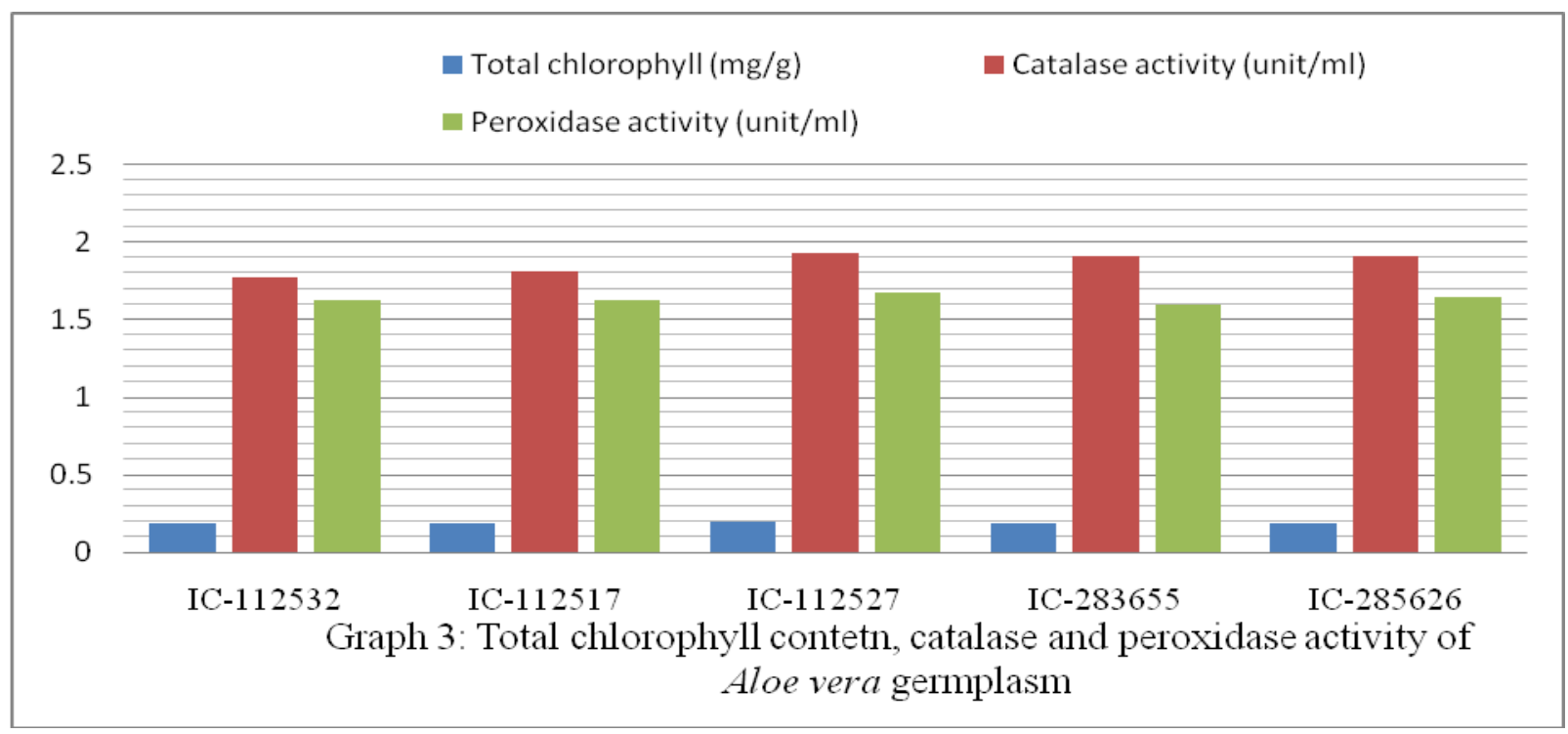

Total chlorophyll content varied from 0.19$0.20(\mathrm{mg} / 100 \mathrm{gm})$ in various germplasm of Aloe vera. Maximum total chlorophyll content was found $0.20(\mathrm{mg} / 100 \mathrm{gm})$ in IC112527 and results found statistically significant themselves. These results are in support of Roy et al., (2007) and Chen Xin Xian et al., (2010).The catalase and peroxidase enzymes play a major role in shelf life of plant because these have antioxidant properties. The catalase activity in varieties ranged from 1.77 to $1.90 \mathrm{unit} / \mathrm{ml}$. Maximum catalase activity was recorded $1.92 \mathrm{unit} / \mathrm{ml}$ in germplasm IC-112527 which was higher among all the germplasm. Germplasm varied statistically significant over all the germplasm. These results have been supported by Hussain (2013) and Ardebili et al., (2012). The peroxidase activity in varieties ranged from 1.59-1.67 unit $/ \mathrm{ml}$. Maximum peroxidase activity was recorded $1.67 \mathrm{unit} / \mathrm{ml}$ in germplasm IC-112527 which is higher as compared to rest other varieties. Germplasm varied statistically significant with each other germplasm. These results are supported by the finding of Hussain (2013) and Ardebili et al., (2012).

Aloe vera has a long history as a medicinal plant with diverse therapeutic applications.
The miraculous medicinal plant Aloe vera has been proved to be a good source of protein, carbohydrate and minerals. It could be used as an important dietary source of nutrients in a food based approach for combating micronutrient deficiency. From the historical era it has been proved that Aloe vera is the sturdy candidate for exploitation as a potential pharmaceutical agent. Aloe gel has been very well known for its use in cosmetics as well as in the other areas of medicine such as its property to heal cancer and treat AIDS. In traditional medicine use of plants shows presence of their therapeutic compounds. In such perspective, testing the biological activity of Aloe vera and related plants demands a special approach. Thus on the basis of biochemical and enzymatic study we can say that germplasm IC-112527, IC285626 and IC-283655 were selected as promising germplasm among all the Aloe vera germplasm.

\section{Acknowledgement}

The author would like to gratefully acknowledge Department of Biochemistry, Narendra Deva University of Agriculture and technology for providing lab facilities for carrying out this work. 


\section{References}

Ardebili, Z.O. Moghadam, A.R.L. and Ardebili, N.O. (2012). The induced by foliar application of amino acids in Aloe vera plant. Plant Omics., 5(3) 279-284.

Arnon, D.I. (1949). Copper enzymes and chlorophyll isolated from chloroplast, polyphenol oxidase in Betavulgaris. Plant Physiol., 24: 1-15.

Dubois, M; Cilles, R.A.; Hamilton, J.K.; Raverm, P.A. and Smith, F. (1950). Estimation of total sugar. Chemistry, Pp. 28-35.

Ganesh, S. and Alagukannang, G. (2009).Growth, yield and quality of ecotype of Aloe vera. Madrsa Agriculture Journal, 96(16): 88-94.

Hamman JH (2008) Composition and applications of Aloe vera leaf gel. Molecules, 13:15991616. DOI: $10.3390 /$ molecules 13081599.

Haque MZ, Rouf MA, Jalil MA, Islam MB, Islam MM, Ahsan MA (2012). Studies on the production of musabbar from Aloe vera. Journal of Advanced Scientific Research, 3(1): 51-54.

Hart, F.L. and Fisher, H.S. (1971).Modern food analysis. Springer verlog: New York.

Hussain, M.A.F. (2013). Chemical composition and biochemical activity of Aloe Vera leafs. International Journal of Chemical and Biochemical Sciences.3:29-33.

McCune, D.C. and Galston, A.W. (1959).Inverse effect of gibberellins on peroxidase activity during growth in dwarf strain of peas and corn. Plant Physio.34:416-418.

Moghaddasi, M. and Verma, S.K. (2011). Aloe vera and their chemical composition and application. International Journal and Biology and Medical resarch. 2(1): 466471.
O'Brien, C. Wyk, A. Van, B.C. and Heerdan, F.R. (2011). Physical and chemical characteristic of Aloe ferox leaf gel. SouthAfrica Journal of Botany. 77(4): 988-995.

Rai S, Sharma DK, Arora SS, Sharma M, Chopra AK (2011) Concentration of the heavy metals in Aloe vera L. (Aloe barbadensis) leaves collected from different geographical locations of India. Ann Biol Re. 2(6):575579 .

Ramachandra CT and Rao PS (2008).Processing of Aloe vera leaf gel: A review, Am. J. Agril. and Biol. Sci.3(2):502-510.

Rangana, S. (1986).Handbook of analysis and quality control for fruit and vegetable products. second edition, New Delhi.

Ray, A., Gupta, S. D., Ghosh, S. (2013). Evaluation of anti-oxidative activity and UV absorption potential of the extracts of Aloe vera L. gel from different growth periods of plants. Industrial Crops and Products. 49:712-719.

Roy, S.K. Mohanty, K. Dey, S.H. and Meikhan, B.C. (2007). Extraction and physicochemical characterization of gel from Aloe vera leaves. J. of Medicinal and Aromatic Plant Sciences. 29(3):131-138.

Singh,R, Pandey, H.K, Joshi, U.C. and Singh, D. (2010). Morphological, biochemical and genetic variability among Aloe vera in Himalayas. Journal of Medicinal and Aromatic Plant Sciences.32(1): 31-36.

Sinha, A.K. (1972). Colorimetric assay of catalse.Anal.Biochemistry.47:2-5.

Varindra, P.D. Joginder, S. and Gosal, S.S. (2011). Biochemical studies of Aloe vera gel of the field and micropropagated plant at different development stage, J. of Plant Biochemistry and Biotechnology. 20(2): 283-287.

\section{How to cite this article:}

Chetna Gangwar, Pratibha Singh, Raj Narayan Kewat and Nitin Vikram. 2017. Biochemical Composition and Enzymatic Activity of Aloe vera (Aloe barbadensis L.). Int.J.Curr.Microbiol.App.Sci. 6(11): 3572-3576. doi: https://doi.org/10.20546/ijcmas.2017.611.419 